\title{
SENSIBILIZAÇÃO AMBIENTAL PARA ALUNOS DOS ANOS INICIAIS DO ENSINO FUNDAMENTAL POR MEIO DA DIVULGAÇÃO CIENTÍFICA: DESVELANDO OS MISTÉRIOS DA LAGOA MÃE-BÁ
}

\author{
Valéria de Oliveira Fernandes ${ }^{1}$ \\ Lidiane Pereira da Silva ${ }^{2}$ \\ Michell Pedruzzi Mendes Araújo ${ }^{3}$
}

Resumo: Esta pesquisa foi realizada com o intuito de transmitir o conhecimento científico obtido por meio das pesquisas do Laboratório de Taxonomia e Ecologia de Algas Continentais ${ }^{4}$ para estudantes dos anos iniciais do ensino fundamental das escolas nas comunidades do entorno da lagoa Mãe-Bá. Foram desenvolvidas atividades que levaram os alunos a conhecerem aspectos ecológicos da lagoa MãeBá, evidenciando a importância das algas como bioindicadoras da qualidade ambiental, bem como a construção do conhecimento em ecologia em um ambiente próximo da realidade desses alunos. Por meio da utilização de questionários e mapas mentais, foi possível mensurar a aprendizagem dos alunos a partir da divulgação científica realizada.

Palavras-chave: Ecossistemas Aquáticos; Mapas Mentais; Sensibilização Ambiental; Lagoas Costeiras; Ensino Fundamental.

Abstract: This research was carried out with the intention of transmitting the scientific knowledge obtained through the research of the Laboratory of Taxonomy and Ecology of Continental Algae for students in the early years of elementary school in the communities surrounding the Mãe-Bá lagoon. Activities were developed that led students to learn about ecological aspects of the Mãe-Bá lagoon, highlighting the importance of algae as bioindicators of environmental quality, as well as the construction of knowledge in ecology in an environment close to the reality of these students. Through the use of questionnaires and mental maps, it was possible to measure students' learning from the scientific dissemination carried out.

Keywords: Aquatic Ecosystems; Mental Maps; Environmental Awareness; Coastal Lagoons; Elementary School.

\footnotetext{
1 Universidade Federal Espírito Santo. E-mail: valeriaufes@yahoo.com.br, Link para o Lattes: http://lattes.cnpq.br/2323760323729607

2 Rede Estadual de Educação do Espírito Santo (SEDU-ES). E-mail: lidypersi@hotmail.com, Link para o Lattes: http://lattes.cnpq.br/3790884848712403

${ }^{3}$ Universidade Federal Espírito Santo. E-mail: michellpedruzzi@yahoo.com.br, Link para o Lattes: http://lattes.cnpq.br/6141634183456644

${ }^{4}$ LATEAC- Universidade Federal do Espírito Santo.
} 


\section{Introdução}

Desde os tempos remotos, o homem tem aproximação com os ecossistemas aquáticos, seja por admiração, lazer, contemplação ou usos que faz destes. Como qualquer outro organismo, depende destes ambientes para sobreviver e, dentre as regiões habitadas no planeta, a costeira é a mais ocupada por grandes centros urbanos.

A importância dos ecossistemas costeiros parte do princípio de que o alimento, a possibilidade de construção de moradia, o lazer, a saúde e outros fatores são ofertados por esses ambientes (FERREIRA, 2008). Neste contexto, encontram-se as lagoas costeiras - corpos d'água presentes em todos os continentes, usualmente orientados paralelos ou perpendiculares à costa, com pequena profundidade e separados do mar por uma barra ou conectados ao oceano por um ou mais canais, de maneira intermitente ou permanente (KJERFVE, 1994).

As lagoas costeiras são ecossistemas de inegável importância ecológica e econômica: estabilizam o clima regional e local; são extremamente ricos em biodiversidade; apresentam levada produtividade biológica; são abrigos e refúgios para inúmeras formas de vida; são fonte de renda para muitas famílias na região por meio do uso de plantas aquáticas para artesanatos, pesca e meio de cultivo para espécies de valor comercial, como tilápias, por meio da piscicultura intensiva. Também presentam múltiplos usos pela população como abastecimento doméstico e industrial, pesca artesanal e/ou comercial, recreação/lazer, irrigação de culturas e harmonia paisagística.

No entanto, o equilíbrio ecológico das lagoas costeiras vem sendo ameaçado há muitas décadas devido a diversas formas de impacto antrópico, tais como lançamento de efluentes domésticos e industriais sem tratamento, coleta e disposição inadequada de resíduos sólidos, destruição da mata ciliar favorecendo a erosão e o aporte de material orgânico/ inorgânico de origem alóctone e, nas últimas décadas, o incremento das atividades de piscicultura intensiva (tanques rede).

Todos estes fatores têm sido apontados como causas da eutrofização aumento considerável da concentração de nutrientes na coluna d'água; pode ocorrer de forma natural ou artificial (ESTEVES, 2011), sendo esta última mais frequente e acelerada.

Segundo Primack e Rodrigues (2001), a quantidade de nitrogênio produzido nos ecossistemas aquáticos pelas atividades humanas é maior do que é consumido nos processos biológicos naturais. Altas concentrações desses nutrientes resultam em sérias consequências, por vezes irreparáveis, nestes ambientes.

Por serem rasas, as lagoas costeiras apresentam elevada biodiversidade e densidade de microalgas, sejam suspensas na coluna d'água (fitoplâncton), sejam aderidas/associadas a algum substrato (rocha, sedimento, macrófitas aquáticas, dentre outros) submerso (perifíton). Ambas as

revista brasileira educação ambiental 
comunidades de microalgas têm papel fundamental em seu funcionamento por se constituírem em fonte alimentar (base das cadeias alimentares) para os demais níveis tróficos e participarem ativamente da ciclagem de nutrientes nestes ambientes; são também excelentes bioindicadores da sua qualidade ecológica.

Em lagoas costeiras livres de impactos antrópicos, as algas fitoplanctônicas e perifíticas são controladas por mudanças climáticas sazonais (chuva, seca, ventos), limitação nutricional e predação. Entretanto, com a eutrofização cada vez mais frequente, as populações de algas crescem em proporção indesejável, causando as "florações" (RAVEN; EVERT; EICHHORN, 2007), as quais alteram a qualidade da água modificando suas características como odor, cor e sabor, além da potencialidade de várias microalgas liberarem substâncias químicas tóxicas para outros microrganismos, causando grande número de mortes e consequentemente, afetando toda a cadeia alimentar, podendo prejudicar as populações humanas que se utilizam de suas águas para múltiplos fins, como abastecimento, pesca, lazer e irrigação.

Apesar do elevado número de lagoas costeiras no Brasil (extenso litoral) e, mais especialmente no estado do Espírito Santo (estima-se que haja mais de 300 lagoas), há ainda muito que se conhecer acerca da dinâmica destes ambientes e das espécies de microalgas que neles vivem (FERNANDES et al, 2009). Muito menor ainda é o conhecimento ecológico da população que vive no entorno e depende das lagoas e do que efetivamente sejam microalgas e sua importância para o ambiente e, de maneira indireta, para o homem.

A segunda maior lagoa costeira em extensão do Estado Espírito Santo, a lagoa Mãe-Bá, está situada entre os municípios de Guarapari e Anchieta e abriga seis aglomerados urbanos: Belo Horizonte, Condados, Goembê, MãeBá, Porto Grande e Monteiro. A lagoa é utilizada para diversos fins, como pesca, área de recreação para comunidades do seu entorno e turistas, harmonia paisagística e abastecimento doméstico. Porém, há várias décadas vem apresentando sinais de eutrofização devido ao lançamento de efluentes de diversas origens.

As poucas pesquisas, sob o ponto de vista ecológico, desenvolvidas neste ambiente (PEREIRA, 2003; LISTON, 2004; MACHADO, 2007; SOUZA, 2008 e COSTA, 2010 - todos avaliando a qualidade da água e/ou as microalgas) mostraram resultados que apontaram para o fato de que a lagoa apresenta alterações negativas nas condições ecológicas. Todavia, nenhum dado foi repassado à população do entorno da lagoa para aumentar seu conhecimento e contribuir com a preservação e/ou discussão de medidas de sua recuperação do ambiente e melhoria da qualidade de vida.

Segundo Araújo, Caluzi e Caldeira (2006) no panorama mundial há forte preocupação e interesse crescente pela alfabetização científica. Muitos projetos vêm sendo elaborados em função da necessidade de tornar mais acessíveis os conhecimentos científicos à população em geral, tendo como 
inspiração os avanços científicos e tecnológicos recentes, bem como as demandas de participação ampla em decisões que envolvem seus impactos na sociedade.

A divulgação científica vem crescendo nos últimos anos, o que é justificado pelo acompanhamento do próprio desenvolvimento da ciência e da tecnologia, o qual faz parte, cada vez mais, do cotidiano dos indivíduos (BORGES; CALDEIRA, 2006).

Quando se fala de divulgação científica, pressupõe-se qualquer forma de comunicação, por meio da qual conseguimos expor uma ideia, um ponto de vista, uma imagem ou qualquer resultado de um trabalho efetuado, segundo os rigores científicos (FILHO, 2006). No entanto, a divulgação pode ser falada, escrita ou demonstrada por uma imagem ou por um som.

A educação formal oferecida pelos sistemas de ensino em escolas, faculdades, universidades e outras instituições foi e continua sendo espaço de sistematização das informações científicas. Porém, não há mais espaço para a escola tradicional que visa o acúmulo de conhecimentos, pois não dá conta de absorver e interpretar a grande quantidade de informações que está exposta rotineiramente. A sala de aula não se constitui mais no único local de aprendizagem.

Segundo Cavassan, Silva e Seniciato (2006) ensinar Ciências requer, a um só tempo, o conhecimento sobre os conteúdos científicos e sobre o modo como os aprendizes atribuem significados ao que está sendo ensinado, o que inclui desde a adoção de determinada metodologia de ensino, passando pelas questões de motivação e envolvimento dos alunos, chegando até a formação de valores que irão nortear a vida prática.

Quando se trata de ensino das Ciências para o Ensino Fundamental, a situação é ainda mais crítica, pois a apreensão de mundo por parte das crianças é dada muito mais em seu aspecto concreto, em seu envolvimento emocional com o assunto, e menos pelas abstrações e generalizações típicas dos conceitos científicos (CAVASSAN; SILVA; SENICIATO, 2006).

A presente pesquisa foi desenvolvida com 0 intuito de transmitir 0 conhecimento científico obtido por meio das pesquisas no LATEAC/UFES (Laboratório de Taxonomia e Ecologia de Algas Continentais) para estudantes dos anos iniciais do ensino fundamental das escolas nas comunidades do entorno da lagoa Mãe-Bá.

Foram desenvolvidas atividades que levaram os alunos a conhecerem aspectos ecológicos do ecossistema aquático em questão (lagoa Mãe-Bá), mostrando a importância das algas como bioindicadoras da qualidade ambiental, bem como a construção do conhecimento em ecologia em um ambiente próximo da realidade desses alunos. Nessas atividades, aspectos subjetivos como as sensações e as emoções interagiram com os processos de raciocínio, resultando em maior motivação em aprender. 


\section{Atividades desenvolvidas}

Foram realizados quatro encontros, cada um em uma escola diferente nos aglomerados urbanos do entorno da lagoa Mãe-Bá (total cinco), onde foram desenvolvidas as seguintes atividades: aplicação de questionários e mapas mentais (antes e após as atividades), apresentação de teatro de fantoches (Anexos 1, 2 e 3), montagem interativa de uma cadeia alimentar, atividades práticas de coleta de microalgas na lagoa Mãe-Bá e imediata observação em microscópio para reconhecimento destes organismos, fato inédito para estes alunos (Figuras 1A a 1D). Os encontros aconteceram no próprio espaço escolar ao longo dos meses de julho a outubro de 2008, com duração mínima de 3 horas por encontro.

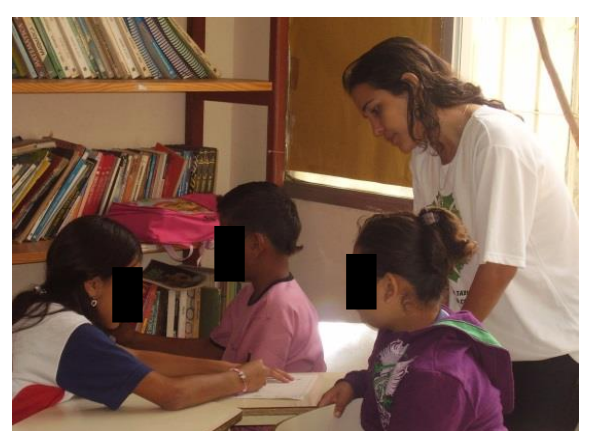

(A)

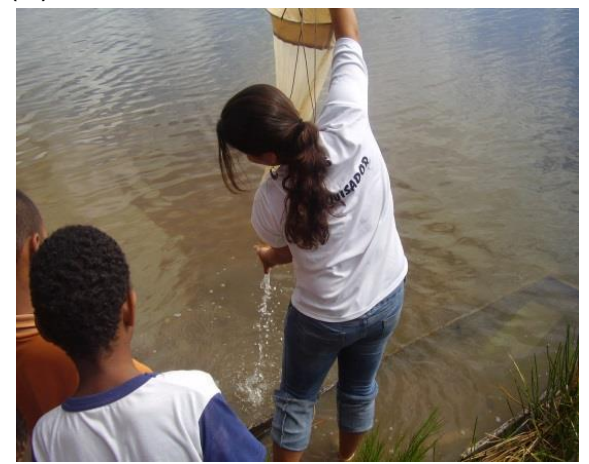

(C)

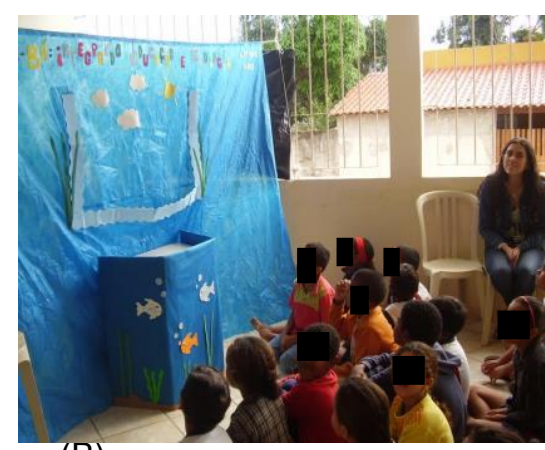

(B)

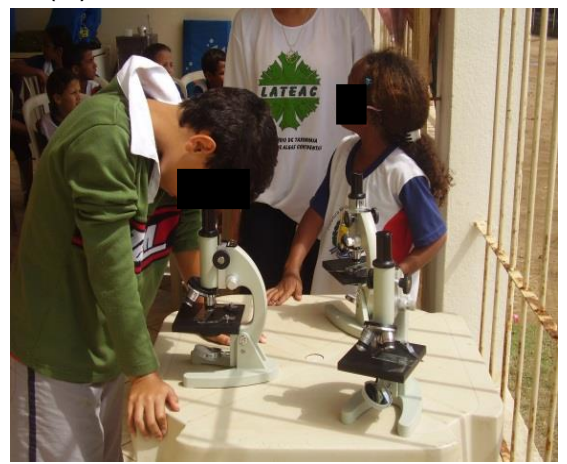

(D)

Figura 1: Atividades realizadas com os alunos em uma das escolas. (A) Aplicação do questionário e mapa mental. (B) Cenário do teatro de fantoches. (C) Atividades prática de coleta na lagoa Mãe-Bá. (D) Observação dos organismos coletados em microscópio óptico.

Fonte: Acervo dos pesquisadores.

\section{Iniciando os trabalhos...}

\section{Questionários e mapas mentais}

Foram abordados nestas duas atividades temas como: usos da água, seres vivos nas lagoas, poluição, mata ciliar e papel de cada um na preservação dos ecossistemas aquáticos. Tanto os questionários quanto os mapas mentais foram aplicados antes e após as atividades de percepção ambiental. 
Nas figuras $2 \mathrm{~A}$ a $2 \mathrm{G}$, estão mostrados os resultados obtidos (em percentuais) quanto aos questionários aplicados aos alunos (avaliação prévia e final) contendo 7 perguntas.

Destaca- se que, de maneira geral, houve mudança em termos de aquisição de conhecimentos por parte dos alunos após atividades propostas, com maior sensibilização ambiental.

A

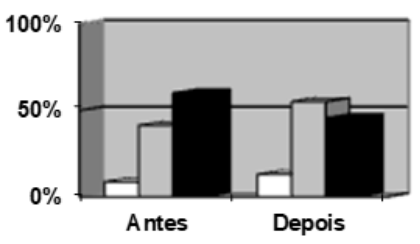

$\square$ Abastecimento $\square$ Habitat $\quad$ Lazer e pesca

C

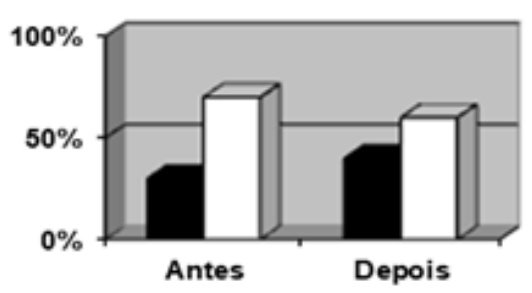

- Sujas alimpas
B

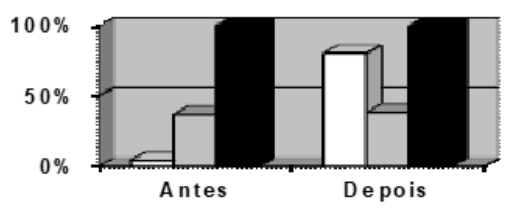

口Microalgas 口Vegetação EAnimais (peixes, sapos,...)

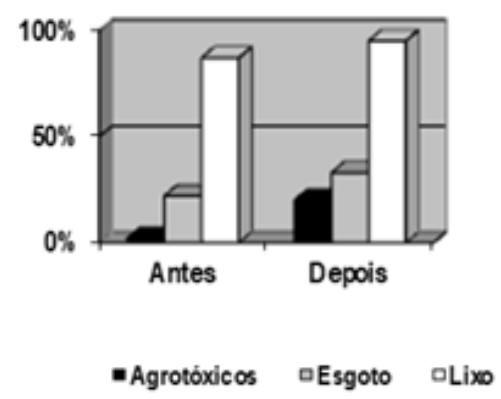

G

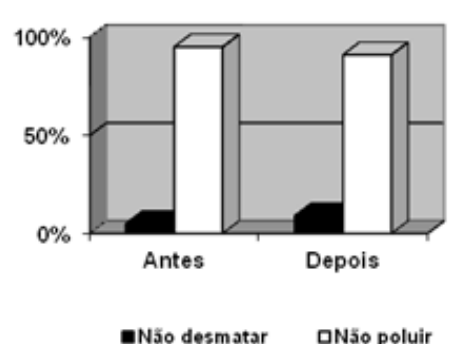

Figura 2: Percentual das respostas dos alunos, antes e depois do questionário: $2 \mathrm{~A}$ (pergunta 1: Que seres vivos você acha que vivem na lagoa - dentro e beira?); 2B (pergunta 2: Para que serve uma lagoa ?); 2C (pergunta 3: As lagoas que você conhece são limpas ou poluídas ?); 2D (pergunta 4: $O$ que você acha que polui as lagoas ?); $2 \mathrm{E}$ (pergunta 5 : Qual a cor das lagoas que você conhece ?); $2 \mathrm{~F}$ (pergunta 6: Tem mata à volta das lagoas que você conhece? ) e 2G (pergunta 7: O que você acha que pode fazer para manter as lagoas limpas?). Fonte: Arquivo dos pesquisadores. 
Os resultados obtidos quanto aos mapas mentais aplicados aos alunos (antes das atividades) estão expressos nas Figuras 3A a 3G. Em todos os desenhos os alunos esquematizaram animais e vegetação dentro ou na beira da lagoa.

Foram destacadas, em cada figura, animais ou atividades que eles já julgavam importantes, tais como: pesca, uso para banho, lixo (pneu, Figura $3 \mathrm{E})$, gado no entorno e placa próximo à lagoa com as palavras "não jogue lixo" (Figura 3F).
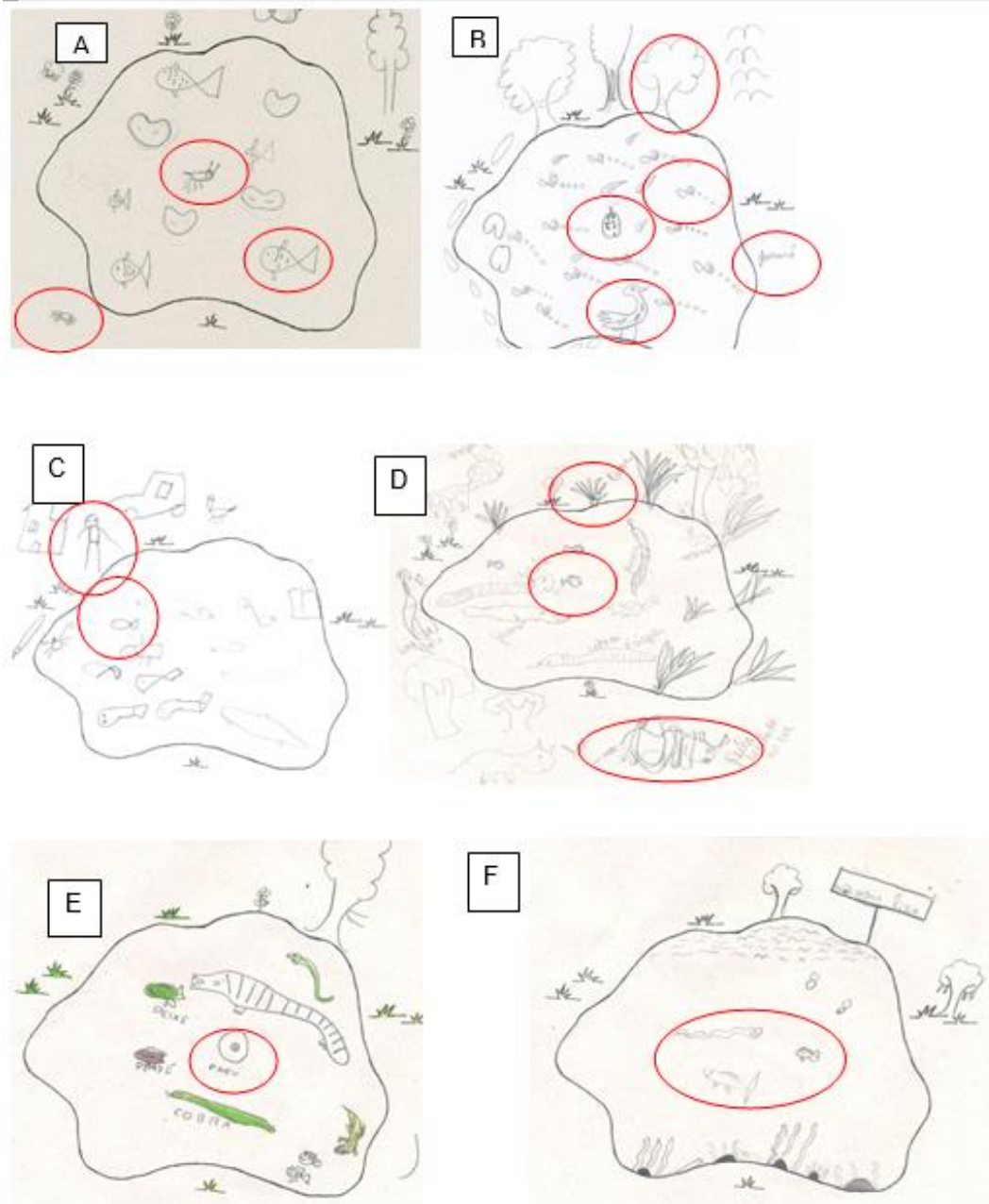

Figura 3: $(A),(B),(C),(D),(E),(F),(G)$ Mapas mentais construídos antes das atividades de divulgação científica realizadas.

Fonte: Acervo dos pesquisadores.

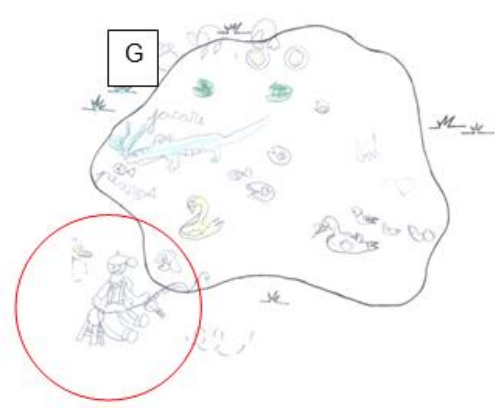

Revbea, São Paulo, V. 15, № 1: 116-130, 2020. 
Após o trabalho realizado, os mapas mentais foram novamente passados aos alunos. Os desenhos feitos por eles revelaram mudanças na forma de pensar e de olharem a lagoa, conforme mostram as figuras $4 \mathrm{H}$ a $4 \mathrm{~J}$, ressaltando microalgas (observadas por eles ao microscópio óptico) e cadeia alimentar.
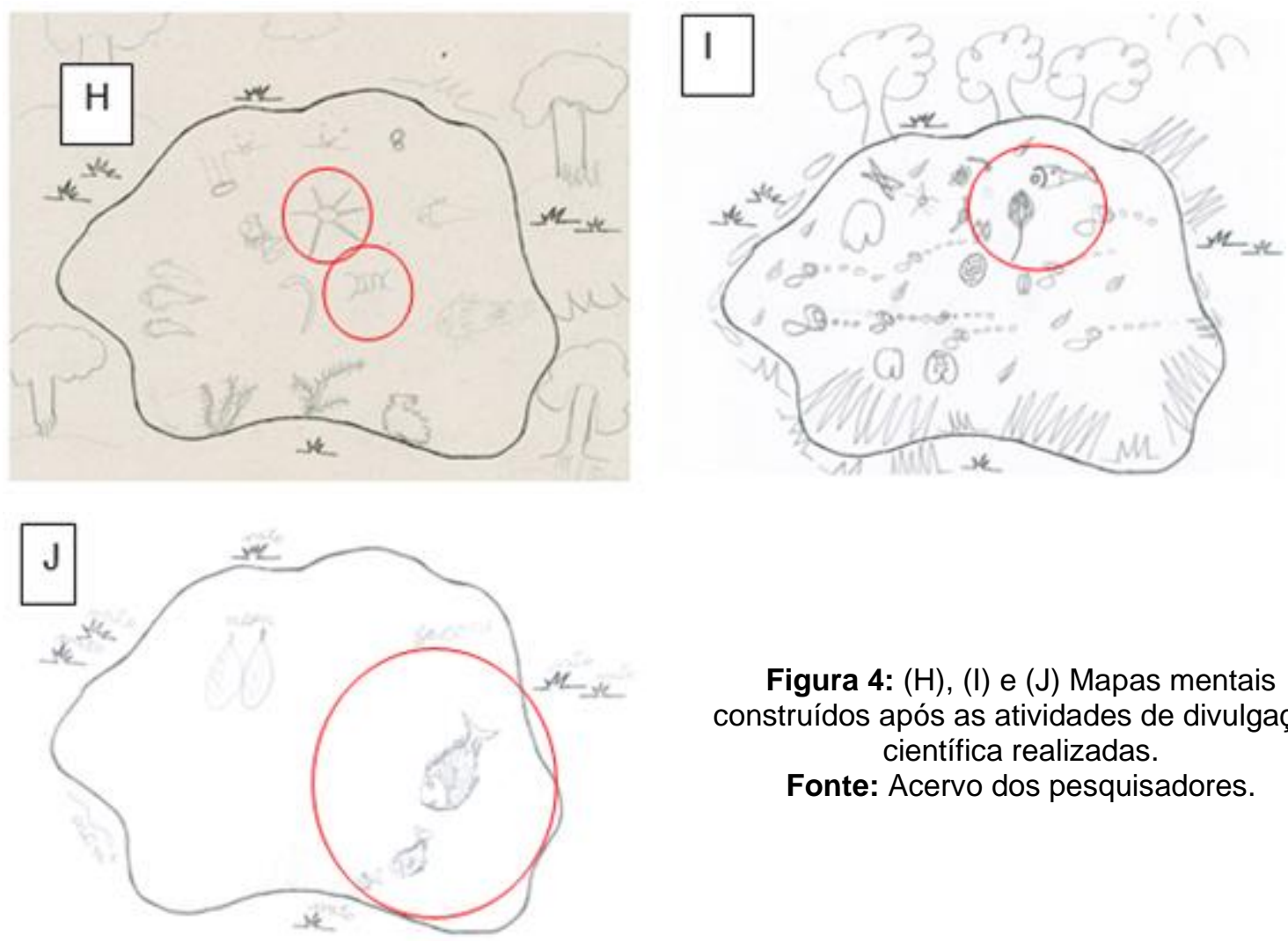

Figura 4: $(\mathrm{H})$, (I) e (J) Mapas mentais construídos após as atividades de divulgação científica realizadas.

Fonte: Acervo dos pesquisadores.

\section{Montagem da cadeia alimentar, teatro de fantoches e observação das microalgas ao microscópio óptico}

No teatro de fantoches foi contada uma história com dois personagens - Amandinha - uma menina curiosa, filha de pescador - e Gilberto - um pesquisador do Lateac/UFES. Nos diálogos, eles trocam experiências e conhecimentos sobre o funcionamento ecológico de uma lagoa, bem como sobre os organismos que nela vivem, com linguagem voltada para crianças. $O$ objetivo desta atividade foi estreitar a relação entre os alunos e a comunidade científica por meio da divulgação científica de forma falada e visual e levar os alunos à construção de conceitos básicos sobre ecologia. Os alunos ouviram atentamente a história e participaram, demonstrando curiosidade e surpresa.

$\mathrm{Na}$ montagem do painel da cadeia alimentar as crianças participaram com entusiasmo, demonstraram interesse pela temática e sentiram-se seguras em colocar cada organismo, principalmente as algas, no respectivo nível da cadeia alimentar (eles montaram a cadeia alimentar após explicação). 
$\mathrm{Na}$ observação ao microscópio óptico, os alunos tiveram a oportunidade de conhecer as microalgas. Curiosidade, interesse e vontade de aprender foram as reações observadas nas crianças durante essa atividade. Todos ficaram surpresos ao visualizar e saber da existência de seres tão pequenos, que não podem ser vistos a olho nu e presentes em grande quantidade em apenas uma gota de água!

\section{Então... os alunos desvendaram os mistérios ecológicos da lagoa?}

\section{Questionários - antes e após as atividades}

O presente trabalho adotou o modelo de pesquisa exploratória, com o objetivo de proporcionar maior familiaridade com o problema, com vistas a torná-lo mais explícito ou a constituir hipóteses (GIL, 2002). Tal abordagem permite aliar as vantagens de se obter dados qualitativos das informações e a possibilidade de quantificá-los. Esta associação realiza-se em nível de complementaridade, possibilitando ampliar a compreensão do fenômeno em estudo (PIOVESAN; TEMPORINI, 1995).

A técnica utilizada para a realização das atividades foi a de estudo de campo. Esta técnica é desenvolvida por meio da observação direta das atividades do grupo estudado e de entrevistas para captar as explicações e interpretações que ocorrem no grupo (GIL, 2002).

O que se observou, analisando as respostas iniciais do questionário, foi que as crianças mostraram aquilo que vivenciavam no dia a dia, seja por elas próprias, seja pela família a qual pertencem. Desta forma, peixes eram componentes da lagoa; gado e taboas existiam no seu entorno; lixo e agrotóxicos como poluidores; pesca e lazer como usos e "não jogar lixo no ambiente" para não poluir.

Assim, o resultado inicial mostrou que as respostas foram influenciadas pela percepção ambiental do sujeito em seu cotidiano e o pouco conhecimento a respeito de ecologia e relações entre os seres vivos e o meio ambiente. Vale ressaltar a presença do conteúdo de ecologia na grade curricular dos anos iniciais do ensino fundamental, de acordo com os Parâmetros Curriculares Nacionais (BRASIL, 1997).

Ressalta-se que nenhum dos alunos na abordagem inicial (questionário prévio) comentou sobre microalgas na lagoa, o que explicita a ausência de conhecimentos sobre estes seres. Já no questionário final, estes serem apareceram na maioria das respostas dos alunos, o que demonstra a assimilação de conteúdos a respeito da riqueza dos organismos que são comuns à lagoa, provavelmente por ter sido transmitido um conhecimento mais amplo, após todas as atividades de divulgação científica e, assim, foram construídos novos conceitos.

Conhecer a diversidade de vida nos ecossistemas, bem como a diversidade de fatores que influenciam e interagem com esses seres vivos, é 
um bom começo para que os alunos entendam as relações ecológicas que ali ocorrem.

As lagoas costeiras são ricas em biodiversidade, apresentam diversas espécies de microalgas e seres que delas dependem para se alimentar, além de plantas aquáticas que servem de refúgio e berçário para muitas espécies de peixes, anfíbios e invertebrados, corroborando o fato de que as atividades propostas neste trabalho ampliaram o conhecimento ecológico dos alunos.

Também é de fundamental importância o entendimento da população que utiliza a lagoa Mãe-Bá a respeito dos fatores que causam a degradação do ambiente e suas consequências ecológicas, econômicas e sociais, não somente para ampliar a reflexão acerca do assunto como também para subsidiar discussões junto aos órgãos competentes para o gerenciamento adequado do ambiente em questão.

Curiosamente, os alunos encaravam a lagoa como sendo um ambiente limpo, de coloração clara e presença de lixo e agrotóxicos como fonte poluidora. Portanto, os alunos apresentaram um conhecimento daquilo que era visualizado por eles no dia a dia de forma superficial e que não houve transmissão de informações específicas no espaço escolar sobre o estado trófico da lagoa e fontes poluidoras.

A falta de conhecimento impediu que os alunos identificassem os sinais de eutrofização artificial da lagoa, dentre eles: coloração esverdeada da água, mau cheiro, proliferação de plantas aquáticas e mortandade de peixes.

Outro ponto importante é que as escolas visitadas estão localizadas na zona rural de Anchieta, o que provavelmente influenciou as respostas em relação à presença de agrotóxicos, já que o uso de tais substâncias é comum à realidade dos alunos.

Com a realização das atividades propostas neste trabalho, principalmente da coleta (campo), os resultados foram diferenciados nas atividades após tais ações, ampliando a visão dos alunos. Houve aumento no percentual de respostas finais que apontaram a poluição na lagoa por meio da presença de lixo, esgotos domésticos e agrotóxicos. Da mesma forma, foram diferentes as respostas finais quanto à coloração da água.

É importante lembrar que diversas pesquisas realizadas na lagoa MãeBá (SOUZA, 2008, LISTON, 2004, entre outras) mostraram elevada quantidade de nutrientes e o crescente processo de eutrofização na lagoa Mãe-Bá, o que ocasiona a proliferação de algas, especialmente cianobactérias, que são potencialmente produtoras de toxinas de ação letal ao homem e a diversos animais da cadeia trófica, promovendo diminuição da qualidade da água e provavelmente a impossibilidade dos usos nobres deste ecossistema.

Os esforços para preservar a biodiversidade, às vezes se chocam com as necessidades humanas. O desenvolvimento sustentável representa uma solução para este confronto. Trata-se de um desenvolvimento econômico que 
satisfaz tanto as necessidades humanas de recursos e emprego presentes quanto as futuras, enquanto minimiza seu impacto sobre a diversidade biológica (PRIMACK; RODRIGUES, 2001).

Nesse caminho, Tristão (2004) comenta que os princípios fundamentais da sustentabilidade estão contemplados nas concepções educativas, ou seja, a perspectiva ética, a mudança de valores e de comportamento dos sujeitos.

Quanto à pergunta sobre como evitar a poluição na lagoa, a maioria dos alunos citou em suas respostas: "não jogar lixo". Os alunos demonstraram que além de atitude ecológica, possuem conhecimento de um ecossistema muito importante para o planeta e, principalmente para a sobrevivência deles, uma vez que a maioria das famílias daquela região tem seu sustento a partir da pesca.

Houve aumento do número de alunos que responderam a favor da preservação de matas no entorno da lagoa. Isso demonstra que os alunos, além de citar os cuidados com a poluição, passaram a associar estas atitudes à preservação e recuperação das matas ciliares. Com isto demonstraram assimilação dos conceitos desenvolvidos sobre a importância da preservação da lagoa, são conscientes do papel como cidadãos em manter saudável esse ecossistema e, a partir disso, levarem o conhecimento científico a outras pessoas.

\section{Mapas mentais - antes e após as atividades}

Observou-se que a maioria dos alunos representou, nos mapas mentais prévios, animais como peixes, aves, insetos, crustáceos, anfíbios, répteis e outros, além de vegetação, principalmente taboa, muito presente em todo o entorno da lagoa.

Alguns representaram pescadores, demonstrando que os alunos são conscientes da relação do homem com o ecossistema. Também foi representada uma menina tomando banho e boi no entorno da lagoa, o que deixa claro a utilização da lagoa como local de lazer para as crianças e que, ao mesmo tempo, percebem a utilização do entorno para a criação de gado.

Notou-se também que os alunos tinham consciência dos impactos causados pelo homem por meio da representação de lixo na lagoa, como pneus. Ao mesmo tempo, os alunos demonstraram preocupação quanto à preservação do ecossistema em estudo.

Segundo Silveira (2002) as representações sociais não são conceitos prontos e acabados, e por esse motivo cada um as interpreta da sua maneira. Esta característica a torna uma excelente metodologia para lidar com a interpretação das imagens, permitindo identificar qual a posição dos sujeitos da pesquisa em relação ao meio em que vivemos. 
Nos mapas mentais construídos após as atividades foram notadas algumas diferenças, evidenciando que os alunos assimilaram novos conhecimentos, como também ocorreu nos resultados dos questionários de avaliação final.

Além dos animais e plantas presentes nos mapas iniciais, algas foram representadas nos desenhos. Ocorreram representações da relação entre os seres vivos na cadeia alimentar, atestando a obtenção de novos conhecimentos por meio das atividades realizadas. Observou-se também um aumento na riqueza de seres vivos ao comparar-se com os mapas iniciais.

Assim, compreendemos que os mapas mentais podem ser utilizados como formas de avaliação de novos conhecimentos, permitem a memorização, organização e representação da informação com o propósito de facilitar 0 processo de aprendizagem como descrevem Macluf, Rodriguez e Beltran (2002).

O mapa mental pode transmitir a imagem de um local vivido ou não pelo indivíduo. De acordo com Nogueira (1994, apud PEREIRA; CAETANO, 2009) as representações mentais são feitas de acordo com o espaço conhecido pelo indivíduo. Este conhecimento é adquirido direta (por meio de percepções dos lugares que the são familiares, os espaços vividos) ou indiretamente por meio de leituras, passeios, e informações de terceiros (revista, livros, jornais, televisão, rádio etc.).

Nesse sentido, vale ressaltar a relevância dos mapas mentais como instrumentos de verificação da construção do conhecimento científico.

\section{Teatro de fantoches, montagem da cadeia alimentar e observação ao microscópio}

A reação das crianças durante o teatro de fantoches, a montagem da cadeia alimentar e a observação ao microscópio traduziu a vontade e o interesse delas em obter novas informações.

$\mathrm{Na}$ montagem da cadeia alimentar a maioria dos alunos apresentou interesse em participar interativamente dessa atividade, que foi realizada logo após o teatro, demonstrando o quanto assimilaram da história que foi contada. Apontavam corretamente os seres vivos que fazem parte de cada nível da cadeia alimentar.

Notou-se que durante a observação das algas no microscópio as crianças estavam empolgadas e curiosas. A motivação e o envolvimento dos alunos demonstraram o interesse pelo aprendizado de novos conhecimentos.

Segundo Cavassan, Silva e Seniciato (2006), o aprendizado por parte das crianças é dado muito mais em seu aspecto concreto, em seu envolvimento emocional com 0 assunto, e menos pelas abstrações e generalizações típicas dos conceitos científicos. 
Ressalta-se que as instituições de pesquisas e as escolas têm, em conjunto, um importante papel para a construção de uma cultura científica. Seja de maneira formal ou informal, num espaço escolar ou não.

Segundo Albagli (1996), a divulgação científica no âmbito cívico deve acontecer com a transmissão de informações científicas voltadas para a ampliação da consciência do cidadão a respeito de questões sociais, econômicas e ambientais associadas ao desenvolvimento científico e tecnológico.

Realizar a divulgação científica por meio de atividades que envolvam os alunos utilizando os recursos de fala, som, imagens e outros (como realizado no presente trabalho), uso de teatro, montagem do painel (cadeia alimentar), aula de campo e prática, representam instrumentos muito poderosos e eficazes para a transmissão do conhecimento.

\section{Considerações finais}

As atividades desenvolvidas nessa pesquisa foram de suma importância para a motivação de crianças, despertando o interesse pelo conhecimento científico. Além disso, contribuiu em aproximar a ciência ao espaço escolar, o que potencializa aprendizagem e o desenvolvimento dos alunos. Pode-se concluir, com os resultados obtidos, que o trabalho de divulgação científica, mesmo em curto prazo, mostrou-se eficaz na construção do conhecimento e ampliação do aprendizado em ecologia do ecossistema em estudo.

Diante da pesquisa realizada, espera-se que a popularização da ciência desperte nos cidadãos práticas sustentáveis na utilização dos recursos naturais que os rodeiam e uma melhor compreensão das relações homemnatureza. Além disso, destaca-se a relevância dos mapas mentais para a análise dos processos de aprendizagem e desenvolvimento das crianças que participaram das atividades de divulgação científica realizadas.

\section{Referências}

ALBAGLI, S. Divulgação científica: informação científica para a cidadania? Ci. Inf. Brasília, 1996, 25 v, n. 3, p. 396-404.

ARAÚJO, E. S. N. N.; CALUZI, J. J.; CALDEIRA, A. M de A. Divulgação científica e ensino de Ciências: estudos e experiências. São Paulo: Escrituras editora, 2006.

BORGES, J. C. F.; CALDEIRA, A. M. A. Divulgação científica e o livro didático no ensino de genética. In: Divulgação científica e ensino de Ciências: estudos e experiências. São Paulo: Escrituras editora, 2006, p. 94-114. 
BRASIL. Ministério da Educação. Secretaria de Educação Fundamental. Parâmetros Curriculares Nacionais. Adaptações Curriculares/ Secretaria de Educação Especial - Brasília: MEC/SEF/SEESP, 1997. 62 p.

CAVASSAN, O.; SILVA, P. G. P.; SENICIATO, T. O ensino de Ciências, a biodiversidade e o cerrado. In: Divulgação científica e ensino de Ciências: estudos e experiências. São Paulo: Escrituras editora, 2006, p. 190-219.

COSTA, A. G. Avaliação da estrutura e dinâmica da comunidade de algas perifíticas na lagoa Mãe-Bá. Universidade Federal do Espírito Santo-UFES. Vitória. 2010. (Monografia).

ESTEVES, F. A. Fundamentos da limnologia. Rio de Janeiro: Interciência, 2011.

FERNANDES, V. O. et al. Lagoa Mãe-Bá (Guarapari-Anchieta, ES): um ecossistema com potencial de floração de cianobactérias? Oecologia Brasiliensis, 13(2): 366-381, 2009.

FERREIRA, J. M. Avaliação da percepção ambiental dos pescadores do projeto piscicultura tendo como base estudos ecológicos na lagoa Mãe-Bá (GuarapariAnchieta, ES). Universidade Federal do Espírito Santo-UFES. Vitória, 2008. (monografia).

FILHO, P.F. S. A divulgação científica em química. In: Divulgação científica e ensino de Ciências: estudos e experiências. São Paulo: Escrituras editora, 2006. p. 115-138.

GIL, A. C. Como classificar as pesquisas? 4.ed. São Paulo: Atlas, 2002.

KJERFVE, B. Coastal lagoon processes. In: KJERFVE, B. (Ed.). Coastal lagoon processes. Amsterdam: Elsevier Oceanography Series, n. 60, 1994. p. 577.

LISTON, G. S. Variação espacial e temporal da comunidade fitoplanctônica em uma lagoa costeira utilizada para abastecimento doméstico no estado do Espírito Santo (Lagoa Maimbá, Guarapari - ES). Vitória. UFES, 2004. p. 57. (Monografia).

MACHADO, R. G. Avaliação da comunidade fitoplanctônica como base para estimativa da qualidade ambiental da lagoa Mãe-Bá (Guarapari-ES). Relatório Final. Programa Institucional de Bolsas de Iniciação Científica (CNPq-UFES). Vitória, 2007. p. 10.

MACLUF, J. E. RODRIGUEZ, J. T. Q; BELTRAN, A. D. Los mapas mentales: uma herramienta de aprendizaje y criatividade. Ciência Administrativa, n.2, Xalapa, 2002.

PEREIRA, A. A. Aspectos qualitativos de águas de lagoas costeiras e seus fatores influentes - estudo de caso: lagoa Mãe-bá. 2003. 147p. Dissertação (Mestrado em Engenharia Ambiental) - Programa de Pós-Graduação em Engenharia Ambiental, Universidade Federal do Espírito Santo, Vitória, 2003. 
PEREIRA, P. R. C.; CAETANO, D. L. N. O potencial dos mapas mentais como instrumento de ensino na Geografia em diferentes níveis de aprendizagem. GOIÁS, 2009. Disponível em: $<$ http://www.erebio.agbjatai.org/anais/textos/85.pdf>. Acesso em 01 de Junho de 2019.

PIOVESAN, A.; TEMPORINI, E. R. Pesquisa exploratória: procedimento metodológico para o estudo de fatores humanos no campo da saúde pública. Rev. Saúde Pública, 29 (4): 318-25. 1995.

PRIMACK, R. B.; RODRIGUES, E. Biologia da Conservação. 3. ed. Londrina: Ed. Rodrigues, 2001.

RAVEN, P. H.; EVERT, R. F.; EICHHORN, S. E. Biologia Vegetal. 7. ed. Guanabara Koogan, 2007.

SILVEIRA, A. M. Propostas metodológicas para a Educação Ambiental: Representação social e interpretação de imagens. Tese de D.S.C., Programa de Pós-graduação em Ecologia e Recursos Naturais/UFSCar. São Carlos, SP, 2002.

SOUZA, B. D. Estrutura, dinâmica e produtividade primária do fitoplâncton como base para estimativa do estado trófico de uma lagoa costeira no Estado do Espírito Santo (lagoa Mãe-Bá, Guarapari). 2008. 159p. Dissertação (Mestrado em Ecologia e Recursos Naturais) - Universidade Estadual do norte Fluminense, Campos dos Goytacazes. 2008.

TRISTÃO, M. A educação ambiental na formação de professores: Rede de saberes. São Paulo: ANNABLUME. p. 40-69, 2004. 